\title{
Surgical Ethics Symposium: Ethical Dilemmas in Surgical Practice
}

\author{
Alberto Ferreres - Peter Angelos
}

Published online: 9 April 2014

(C) Société Internationale de Chirurgie 2014

\section{Introduction by the guest editors}

We have been asked to be Guest Editors for a Symposium on Surgical Ethics referring to Ethical Dilemmas in Surgical Practice, sponsored by the International Society for Digestive Surgery (ISDS). This being a concern for all those involved in surgical care all over the world, we bring together a very inclusive panel of experts from different countries to give a thorough overview about these worldwide issues.

Through this symposium, we would like to give answers and guidelines for two main aspects:

1. Is there really a 'surgical ethics'?

2. Which are the dilemmas any surgeon around the world will confront during his or her daily practice?

McCullough et al. [1] were the first to examine the scope of surgical ethics. They define surgical ethics by the way in which the procedural nature of surgery and its capacity for bodily and psychic damage modify general ethical considerations such as virtues, consequences, rights, justice, and equality. Their point of view is that the ethics of surgery is a special case of the general ethics of medicine.

Yet, there is something distinctive about surgery. According to Little [2, 3], surgical ethics is set apart from general medical ethics by five categories within the moral domain of the surgical relationship. These five categories are rescue, proximity, ordeal, aftermath, and presence, and all of them are experienced by the patients. The surgeon's presence to the patient throughout these experiences is the ethical response that best fits the patient's needs. Thus, presence is ethically normative.

Most of the aspects of the patient-surgeon relationship are discussed, as well as the dilemmas a surgeon confronts in his or her everyday practice towards surgical patients. The distinguished co-authors have done an impressive job putting together a very thorough and insightful compendium about surgical ethics, which, we have no doubt, will serve those involved in surgical care all over the world.

A special acknowledgement to all our patients, whose gratitude should be the most highly regarded.

\section{References}

1. McCullough LB, Jones JW, Brody BA (1998) Surgical ethics. Oxford University Press, New York

2. Little M (2002) The fivefold root of an ethics of surgery. Bioethics 16(3):183-201

3. Little M (2001) Invited commentary: is there a distinctively surgical ethics? Surgery 129:668-671

\footnotetext{
A. Ferreres $(\bowtie)$

Department of Surgery, University of Buenos Aires,

Buenos Aires, Argentina

e-mail: albertoferreres@gmail.com

P. Angelos

MacLean Center for Clinical Ethics, University of Chicago,

Chicago, IL, USA
} 